\title{
ANALISIS KELAYAKAN USAHA PETERNAKAN AYAM RAS PETELUR DI KECAMATAN PRAYA BARAT DAYA KABUPATEN LOMBOK TENGAH
}

\section{FEASIBILITY ANALISYS OF LAYING CHICKEN FARMING BUSINESS IN PRAYA BARAT DAYA SUBDISTRICT, CENTRAL LOMBOK REGENCY}

\author{
Nurul Hidayati ${ }^{*}$, Sri Maryati ${ }^{2}$ dan Muhammad Zubair ${ }^{3}$ \\ ${ }^{1}$ Mahasiswa Program Studi Agribisnis Fakultas Pertanian Universitas Mataram \\ ${ }^{2,3}$ Dosen Program Studi Agribisnis Fakultas Pertanian Universitas Mataram \\ "E-mail: nh8573520@gmal.com
}

\begin{abstract}
ABSTRAK
Penelitian ini bertujuan untuk: (1) Menganalisis pendapatan usaha peternakan ayam ras petelur di Kecamatan Praya Barat Daya Kabupaten Lombok Tengah; (2) Menganalisis kelayakan usaha peternakan ayam ras petelur di Kecamatan Praya Barat Daya Kabupaten Lombok Tengah; (3) menganalisis kendala-kendala yang dihadapi dalam usaha peternakan ayam ras petelur di Kecamatan Praya Barat Daya Kabupaten Lombok Tengah. Penelitian ini menggunakan metode deskriptif, dimana penelitian ini dilakukan di Kecamatan Praya Barat Daya yaitu Desa Darek yang ditetapkan secara "purposive sampling" dengan jumlah responden sebanyak 4 orang peternak. Analisis data yang digunakan yaitu analisis pendapatan, net present value, internal rate of return, net benefit cost ratio, payback period, deskriptif. Hasil penelitian menunjukkan (1) Rata-rata pendapatan peternak dalam dua kali siklus produksi sebesar Rp. 112.823.067 untuk peternak tipe I dan rata-rata pendapatan yang diperoleh sebesar peternak tipe II sebesar Rp. 80.499.988/dua kali siklus produksi. (2) Usaha peternakan ayam ras petelur di Kecamatan Praya Barat Daya Kabupaten Lombok Tengah layak untuk dikembangkan, hal ini dapat dilihat dari perolehan nilai NPV sebesar Rp. 76.131.921, nilai IRR sebesar 2,58\%/ bulan, nilai Net B/C sebesar 1,33, dan PBP dapat dicapai dalam jangka waktu 8 bulan 27 hari untuk peternak tipe I Sedangkan untuk peternak tipe II, nilai NPV sebesar Rp. 13.987.52 nilai IRR sebesar 1,54\%/bulan, nilai Net B/C sebesar 1.08, dan PBP dapat dicapai dalam jangka waktu 11 bulan 13 hari. (3) Kendala yang dihadapi peternak adalah serangan penyakit, cuaca tidak menentu, dan mahalnya harga pakan.
\end{abstract}

Kata kunci: peternakan ayam ras petelur, pendapatan, kelayakan usaha.

\section{ABSTRACT}

This study aims to: (1) Analyze the income of laying chicken business in Southwest Praya Subdistrict, Central Lombok Regency; (2) Analyze the feasibility of laying chicken business in Southwest Praya Subdistrict, Central Lombok Regency; (3) analyze the problems faced in laying chicken business in Southwest Praya Subdistrict, Central Lombok Regency. This study used descriptive method, in which this study was conducted in Praya Barat Daya Subdistrict, Darek Village, which was set by "purposive sampling" with 4 farmers as the respondent. The data analysis used is income analysis, net present value, internal rate of return, net benefit cost ratio, payback period, descriptive. The results of the study shows (1) The average income of farmers in the two production cycles of Rp. 112,823,067 for type I Farmers and the average income earned is as big as type II farmers of Rp. 80,499,988/ twice of the production cycle. (2) Laying chicken farms in Southwest Praya Subdistrict, Central Lombok Regency are feasible to be developed, it can be seen from the acquisition of NPV value of Rp. 76,131,921, IRR value of $2.58 \% /$ month, Net B / C value of 1.33 , and PBP can be achieved within 8 months and 27 days for type I farmers. As for type II farmers, the NPV value is Rp. 13,987.52 IRR value of $1.54 \% /$ month, Net B / C value of 1.08, and PBP can be achieved within 11 months and 13 days. (3) the problems faced by farmers are disease attacks, uncertain weather, and high price of feed.

Key words: laying chicken farms, income, business feasibility.

Hidayati, N., Maryati, S., dan Zubair, M.

Volume 28 Nomor 2 Agustus 2018 


\section{PENDAHULUAN}

Konsumsi masyarakat Indonesia terhadap telur ayam ras pada tahun 2018 sebesar 10,44 $\mathrm{Kg}$ per orang, diperkirakan jumlah tersebut akan terus mengalami peningkatan. Hal ini disebabkan oleh harga telur ayam ras yang sangat kompetitif, dan lebih murah dibandingkan jenis telur lainnya. Adapun kontribusi ayam ras petelur terhadap produksi total telur di Indonesia sejak tahun 2016-2017 selalu lebih besar dibandingkan dengan telur yang berasal dari unggas lainnya. Produksi telur di Indonesia tahun 2016 sebesar 1.485.687,93 ton, dan produksi tahun 2017 sebesar 1.527.134,87 ton (Sekretariat Jendral Kementrian Pertanian, 2018).

Provinsi Nusa Tenggara Barat (NTB) merupakan salah satu Provinsi yang berkontribusi sebesar 10.392 ton atau $0,68 \%$ pada tahun 2017 terhadap produksi total telur ayam ras di Indonesia. Produksi telur ayam ras di Provinsi NTB mengalami peningkatan dari tahun ketahun (Sekretariat Jendral Kementrian Pertanian, 2018). Peningkatan tersebut di sebabkan oleh meningkatnya jumlah populasi ayam ras petelur di NTB.

Kabupaten Lombok Tengah merupakan kabupaten dengan populasi ayam ras petelur tertinggi kedua setiap tahunnya di Provinsi NTB, dengan jumlah populasi ayam ras petelur tahun 2015 sebanyak 59.064 ekor. Kecamatan Praya Barat Daya merupakan salah satu kecamatan di Lombok Tengah yang terdapat peternakan ayam ras petelur. populasi ayam ras petelur di Kecamatan Praya Barat Daya pada tahun 2017 sebanyak 1.869 ekor $(1,84 \%)$ dari total populasi ayam ras petelur di Kabupaten Lombok Tengah. Jumlah populasi ayam ras petelur di Kecamatan Praya Barat Daya dapat dikatakan masih rendah, karena jumlah populasi ayam ras petelur di kecamatan tersebut masih dibawah rata-rata total populasi ayam ras di Kabupaten Lombok Tengah yang diketahui sebanyak 8.000 ekor.

Kenaikan harga telur ayam ras tidak meningkat signifikan seiring dengan kenaikan harga pakan, sehingga usaha peternakan ayam ras petelur sangat rentan dalam perkembangannya. Karena itu, peluang untuk mendapat keuntungan maupun kerugian sangat besar kemungkinannya dalam usaha peternakan ayam ras petelur.

Berdasarkan uraian di atas maka perlu dilakukan penelitian yang berjudul "Analisis Kelayakan Usaha Peternakan Ayam Ras Petelur Di Kecamatan Praya Barat Daya Kabupaten Lombok Tengah".

Penelitian ini bertujuan (1) Menganalisis pendapatan usaha peternakan ayam ras petelur di Kecamatan Praya Barat Daya Kabupaten Lombok Tengah; (2) Menganalisis kelayakan usaha peternakan ayam ras petelur di Kecamatan Praya Barat Daya Kabupaten Lombok Tengah; (3) menganalisis kendala-kendala yang dihadapi dalam usaha peternakan ayam ras petelur di Kecamatan Praya Barat Daya Kabupaten Lombok Tengah.

\section{METODOLOGI PENELITIAN}

Penelitian ini menggunakan metode penelitian deskriptif dimana pengumpulan data dilakukan melalui wawancara langsung dengan peternak ayam ras petelur di Kecamatan Praya Barat Daya Kabupaten Lombok Tengah.Unit analisis dalam penelitian ini adalah peternakan ayam ras petelur di Kecamatan Praya Barat Daya Kabupaten Lombok Tengah. Penelitian ini dilakukan di Desa Darek Kecamatan Praya Barat Daya Kabupaten Lombok Tengah dengan pertimbangan bahwa daerah tersebut memiliki usaha peternakan ayam ras petelur yang telah dijalani selama lebih dari dua tahun. Penentuan daerah sampel dilakukan dengan metode "purposive sampling". Penentuan jumlah responden dalam penelitian ini dilakukan secara "purposive sampling" yaitu ditetapkan sebanyak 4 responden. Ke 4 responden tersebut di kelompokan menjadi 2 tipe peternak yakni peternak yang menggunakan ayam umur 2 hari pada awal pemeliharaan (peternak tipe I) dan peternak yang menggunakan ayam umur 3 bulan pada awal pemeliharaan (peternak tipe II). Dari ke 4 responden tersebut, 1 responden/peternak tergolong peternak tipe I, dan 3 responden/peternak tergolong peternak tipe II. Jenis data yang digunakan dalam penelitian ini adalah data kualitatif dan data kuantitatif. Sumber data dalam penelitian ini adalah sumber data primer dan data sekunder. Dan pada penelitian ini umur proyek yang digunakan adalah 2 kali siklus produksi (48 bulan). (a) Biaya (b) Penerimaan (c) Pendapatan (d) Kelayakan usaha (e) Kendala-kendala yang dihadapi.

Untuk menghitung jumlah pendapatan petani digunakan rumus:

\section{$\Pi=\mathrm{TR}-\mathrm{TC}$}

Keterangan: $\pi \quad$ : pendapatan petani

TR : total revenue

TC : total cost

Untuk menentukan kelayakan usaha digunakan kriteria kelayakan investasi, yakni :

Net Present Value, yang merupakan selisih antara benefit yang telah didiskon faktor dengan biaya yang telah didiskon faktor.

$$
N P V=\sum_{i=1}^{n} \frac{B_{t}-C_{t}}{(1+i)^{t}}=P V B-P V C
$$

Keterangan : 
$B_{t}=$ Penerimaan pada tahun ke $\mathrm{t}$

$C_{t}=$ Biaya pada tahun ke $\mathrm{t}$

$i=i$ Tingkat suku bunga kredit investasi

$n=i$ Umur ekonomis proyek

Kriteria :

$\mathrm{NPV}>0$, artinya usaha layak untuk dikembangkan.

NPV $<0$, artinya usaha tidak layak untuk dikembangkan.

Internal rate of return, merupakan IRR merupakan nilai discount rate-i yang membuat NPV $=0$. Menurut Kasmir \& Jakfar (2003) Rumus yang digunakan untuk menghitung IRR adalah :

$I R R=i_{1}+\frac{N P V_{1}}{i \dot{i} \dot{r}}$

Keterangan :

$i_{1}=i$ Tingkat discount rate yang menghasilkan $N P V_{1}$

$i_{2} \quad=$ Tingkat discount rate yang menghasilkan $N P V_{2}$

Kriteria :

IRR > Tingkat diskon, maka usaha layak untuk dikembangkan.

IRR $<$ Tingkat diskon, maka usaha tidak layak untuk dikembangkan.

Net Benefit Cost Ratio, Net B/C merupakan perbandingan antara jumlah NPV positif dengan jumlah NPV negatif. Hal ini menunjukan bahwa besarnya benefit berapa kali besarnya biaya dan investasi untuk memperoleh suati manfaat (Pasaribu, 2012).

$$
\operatorname{Net} \mathrm{B} / \mathrm{C} i \frac{\sum_{t=i}^{n} \frac{B_{t}-C_{t}}{(1+i)^{t}}}{\sum_{t=i}^{n} \frac{B_{t}-C_{t}}{(1+i)^{t}}}=\sum_{t=i}^{n} N P V i i \dot{i}
$$

Keterangan :

$B_{t}=$ Penerimaan pada tahun ke $\mathrm{t}$

$C_{t}=$ Biaya pada tahun ke $\mathrm{t}$

$i=i$ Tingkat suku bunga kredit investasi

$t=i$ Umur ekonomis proyek

Kriteria :

NBCR $>1$ dianggap layak

$\mathrm{NBCR}<1$ dianggap tidak layak

$\mathrm{NBCR}=1$ dianggap pulang pokok

Payback Period, merupakan teknik penilaian terhadap jangka waktu (periode) pengembalian investasi suatu proyek atau usaha. Menurut Ibrahim (1997) Rumus yang digunakan untuk menghitung IRR adalah :

$$
P B P=T_{p-1}+\frac{\sum_{i=1}^{n} \overline{I i}-\sum_{i=1}^{n} \overline{B_{i c p-1}}}{\overline{B_{p}}}
$$

Keterangan :

$T_{p-1} \quad=$ tahun sebelum terdapat PBP

$\overline{I i} \quad=$ jumlah investasi yang telah didiscount

$\overline{B_{(i c p-1)}}=$ jumlah benefit yg telah didiscount sebelum PBP

$\overline{B_{p}} \quad=$ jumlah benefit pada PBP berada

Kriteria:

PBP > umur ekonomis usaha, maka usaha tidak layak untuk dikembangkan.

$\mathrm{PBP}<$ umur ekonomis usaha, maka usaha layak untuk dikembangkan. 
Untuk mengetahui apa saja yang menjadi kendala para peternak dalam menjalankan usaha peternakan ayam ras petelur yaitu dengan cara mewawancarai responden secara langsung, kemudian dianalisis secara deskriptif.

\section{HASIL DAN PEMBAHASAN}

Analisis Usaha Peternakan Ayam Ras Petelur

\section{Gambaran Umum Usaha Peternakan Ayam Ras Petelur}

Kegiatan yang dilakukan dalam usaha ini adalah pemberian pakan dan minum, vitamin dan suplemen, obatobatan dan vaksin, pembersihan kandang, dan pengambilan telur. Pemberian pakan dilakukan 2 kali sehari yakni pagi pada pukul 07.00 WITA dan siang pada pukul 13.00 WITA. Kuantitas pakan yang diberikan oleh peternak berbeda untuk setiap fase pertumbuhannya, fase starter (1-12 minggu) kebutuhan pakannya sebesar 0,04 - 0,05 $\mathrm{kg} /$ ekor/hari, untuk fase grower (13-17 minggu) kebutuhan pakannya sebesar 0,06 kg/ekor/hari, sedangkan untuk fase layer (18 minggu) sampai afkir kebutuhan pakannya sebesar 0,11-0,12 kg/ekor/hari. Hal ini dimaksudkan agar ayam memperoleh nutrisi yang sesuai dengan umur dan periodenya, sehingga diharapkan dapat meningkatkan produksi telur. Pemberian vaksin dilakukan dilakukan untuk meningkatkan kekebalan tubuh ayam serta mencegah penyakit yang menyerang ayam. Obat-obatan diberikan ketika ayam terserang penyaki. Pemberian vaksin dilakukan dengan cara suntik, sedangkan pemberian obat dilakukan dengan mencampur dengan air atau pakan ayam. Pembersihan kandang dilakukan setiap hari, dan untuk penyemprotan kandang dengan desinfecta dilakukan sekali dalam seminggu. Pengambilan telur dilakukan setiap hari pada sore hari. Kandang peternakan ayam ras petelur di Kecamatan Praya Barat Daya menggunakan kandang litter yang digunakan untuk DOC, kandang battery bertingkat dan kandang panggung dengan sistem cage yang digunakan untuk ayam dewasa.

Umur ayam yang digunakan oleh peternak pada awal pemeliharaan berbeda-beda, yakni umur 2 hari (DOC), umur 3 bulan (Pullet/dewasa), dan umur 5 bulan (siap bertelur). Dari ke 4 responden tersebut, 3 orang peternak yang memelihara ayam dari umur 3 bulan (pullet/dewasa) dengan skala usaha rata-rata 667 ekor, dan sisanya 1 orang peternak memelihara ayam dari umur 2 hari (DOC) dengan skala usaha 1100 ekor.

\section{Struktur Biaya Usaha Peternakan Ayam Ras Petelur}

Dalam penelitian ini komponen biaya terdiri dari biaya tetap dan biaya variabel yang digunakan dalam analisis pendapatan, serta biaya investasi dan biaya operasional yang digunakan dalam analisis kelayakan usaha.

\section{Biaya Tetap}

Biaya tetap (Fixed Cost) adalah biaya yang dikeluarkan oleh peternak ayam ras petelur di Kecamatan Praya Barat Daya Kabupaten Lombok Tengah, yang penggunaannya tidak habis dalam sekali produksi. Adapun rincian dari biaya tetap disajikan pada Tabel 1

Tabel 1. Rata-rata Biaya Tetap Usaha Peternakan Ayam Ras Petelur di Kecamatan Praya Barat Daya Kabupaten Lombok Tengah

\begin{tabular}{|c|c|c|c|c|c|}
\hline \multirow[t]{2}{*}{ No } & \multirow[t]{2}{*}{ Uraian } & \multicolumn{2}{|c|}{ Peternak Tipe I } & \multicolumn{2}{|c|}{ Peternak Tipe II } \\
\hline & & $\begin{array}{c}\text { Biaya }(\mathrm{Rp} / \mathrm{siklus} \\
\text { Produksi) }\end{array}$ & $\begin{array}{l}\text { Biaya ( } \mathrm{Rp} / \text { total } \\
\text { siklus produksi) }\end{array}$ & $\begin{array}{c}\text { Biaya } \\
\text { (Rp/siklus } \\
\text { produksi) }\end{array}$ & $\begin{array}{l}\text { Biaya (Rp/total } \\
\text { siklus produksi) }\end{array}$ \\
\hline 1. & $\begin{array}{l}\text { Penyusutan } \\
\text { Peralatan }\end{array}$ & 3.398 .966 & 6.797 .932 & 2.121 .974 & 4.243 .948 \\
\hline 2. & $\begin{array}{l}\text { Penyusutan } \\
\text { Kandang }\end{array}$ & 10.000 .000 & 20.000 .000 & 7.027 .778 & 14.055 .556 \\
\hline 3. & $\begin{array}{l}\text { Penyusutan } \\
\text { Kandang } \\
\text { Baterai }\end{array}$ & 7.500 .000 & 15.000 .000 & 1.782 .407 & 3.564 .815 \\
\hline
\end{tabular}




\begin{tabular}{ccccc}
\hline $4 . \quad \begin{array}{c}\text { Pengembalian } \\
\text { Modal } \\
\text { Pinjaman }\end{array}$ & 112.800 .000 & 112.800 .000 & - & - \\
\hline Total & 133.698 .966 & 154.597 .933 & 10.932 .159 & 21.864 .319 \\
\hline
\end{tabular}

Sumber: Data Primer Diolah, (2019)

Biaya tetap terdiri dari penyusutan peralatan, penyusutan kandang (gudang), penyusutan kandang baterai, dan pengembalian pinjaman. Tabel 1 menunjukan bahwa total biaya tetap yang dikeluarkan oleh peternak tipe I sebesar Rp. 133.698.966 per siklus produksi atau Rp. 154.597.933 per total siklus produksi. Sedangkan untuk peternak tipe II, rata-rata total biaya tetap yang dikeluarkan oleh peternak tipe I sebesar Rp. 10.932.159 per siklus produksi atau Rp. 21.864.319 per total siklus produksi. Pengembalian pinjaman ini hanya di keluarkan oleh peternak tipe I dan pada proses produksi yang pertama, karena pada saat melakukan proses produksi yang selanjutnya, modal yang digunakan merupakan modal sendiri.

\section{Biaya Variabel}

Biaya variabel adalah biaya yang besar kecilnya akan berpengaruh terhadap hasil produksi. Adapun rincian dari biaya tetap disajikan pada Tabel 2 .

Tabel 2. Biaya Variabel Usaha Peternakan Ayam Ras Petelur di Kecamatan Praya Barat Daya Kabupaten Lombok Tengah

\begin{tabular}{llrrrr}
\hline & & \multicolumn{2}{l}{ Peternak Tipe I } & \multicolumn{2}{l}{ Peternak Tipe II } \\
\cline { 3 - 6 } NO & Uraian & $\begin{array}{l}\text { Biaya } \\
\text { Rp/siklus }\end{array}$ & $\begin{array}{l}\text { Biaya (Rp/total } \\
\text { siklus produksi) }\end{array}$ & $\begin{array}{l}\text { Biaya } \\
\text { (Rp/siklus } \\
\text { produksi) }\end{array}$ & $\begin{array}{l}\text { Biaya (Rp/total } \\
\text { siklus produksi) }\end{array}$ \\
\hline $\mathbf{1}$ & Sarana Produksi & 482.239 .500 & 964.479 .000 & 326.306 .180 & 652.612 .360 \\
$\mathbf{2}$ & Tenaga Kerja & 36.000 .000 & 72.000 .000 & 22.000 .000 & 44.000 .000 \\
$\mathbf{3}$ & Listrik dan Air & 480.000 & 960.000 & 1.576 .667 & 3.153 .333 \\
$\mathbf{4}$ & Transportasi dan & 4.080 .000 & 8.160 .000 & 1.540 .000 & 3.080 .000 \\
\hline & Perbaikan Kandang & 522.799 .500 & 1.045 .599 .000 & 351.422 .847 & 702.845 .693 \\
\hline Total & & & & &
\end{tabular}

Sumber: Data Primer Diolah, (2019)

Biaya pakan yang termasuk ke dalam biaya sarana produksi merupakan biaya terbesar dalam biaya variabel yang dikeluarkan oleh peternak. Hal ini sesuai dengan pendapat Mulyantini (2010) dalam Maulanan (2017) bahwa pembelian pakan akan menyumbangkan nilai terbesar karena pakan sebagai kebutuhan pokok ayam petelur dan jumlahnya pun ditentukan oleh jumlah ayam yang ada. Semakin banyak ternak yang dipelihara makan pakan yang dibutuhkan dan jumlah pembelian pakan semakin besar. Pakan ayam petelur merupakan input variabel yang sangat besar pengaruhnya terhadap produksi dan keuntungan. Mustika (2011) menyatakan bahwa harga pakan memberi pengaruh negatif terhadap pendapatan, tingginya harga pakan akan menurunkan pendapatan, sebaliknya semakin rendah harga pakan maka pendapatan akan meningkat.

\section{Biaya Investasi}

Biaya investasi adalah biaya yang dikeluarkan untuk membiayai kegiatan bisnis di awal usaha, dan jumlahnya cukup besar. Untuk lebih jelasnya mengenai biaya investasi yang digunakan dalam usaha peternakan tersebut dapat dilihat pada Tabel 3.

Tabel 3. Rata-rata Biaya Investasi Usaha Peternakan Ayam Petelur di Kecamatan Praya Barat Daya Kabupaten Lombok Tengah

\begin{tabular}{|c|c|c|c|c|c|}
\hline \multirow[b]{2}{*}{ No } & \multirow{2}{*}{$\begin{array}{l}\text { Komponen } \\
\text { Biaya Investasi }\end{array}$} & \multicolumn{2}{|c|}{ Peternak Tipe I } & \multicolumn{2}{|c|}{ Peternak Tipe II } \\
\hline & & Nilai (Rp) & $\begin{array}{l}\text { Persentase } \\
(\%)\end{array}$ & Nilai (Rp) & $\begin{array}{l}\text { Persentase } \\
(\%)\end{array}$ \\
\hline 1 & Kandang (Gudang) & 50.000 .000 & 34,33 & 38.333 .333 & 25,77 \\
\hline 2 & Kandang Baterai & 37.500 .000 & 25,75 & 5.833 .333 & 3,92 \\
\hline 3 & Peralatan & 14.649 .000 & 9.99 & 9.302 .500 & 6,25 \\
\hline
\end{tabular}




\begin{tabular}{llrrrr}
$\mathbf{4}$ & Modal Kerja & 21.788 .500 & 14,96 & 47.633 .333 & 32,03 \\
$\mathbf{5}$ & Reinvestasi & 21.788 .500 & 14,96 & 47.633 .333 & 32,02 \\
\hline Total Biaya Investasi & 145.626 .000 & 100 & 148.735 .833 & 100 \\
\hline
\end{tabular}

Sumber: Data Primer Diolah, (2019)

Tabel 3 menunjukan bahwa biaya investasi untuk peternak tipe I sebesar Rp. 145.626.000. Biaya pembuatan kandang merupakan komponen biaya investasi yang paling besar, yakni mencapai 34,33\% dari biaya investasi yang dibutuhkan. Modal yang digunakan untuk usaha ayam ras petelur ini tidak semuanya berasal dari modal sendiri, namun juga berasal dari pinjaman pihak Bank sebesar Rp. 100.000.000 yang harus dikembalikan setiap bulannya, dan sisanya sebesar Rp. 45.626 .000 yang merupakan modal sendiri. Sedangkan biaya investasi untuk peternak tipe II, rata-rata sebesar Rp. 148.735.833 yang merupakan modal sendiri. Komponen biaya investasi paling besar yang harus dikeluarkan peternak tersebut adalah biaya modal kerja yakni sebesar 32,02\% dari keseluruhan biaya investasi yang dibutuhkan, hal ini dikarenakan biaya pembelian bibit ayam yang merupakan komponen modal kerja yang harus dikeluarkan cukup besar yakni rata-rata sebesar Rp. 40.000.000, mengingat bibit ayam yang digunakan adalah ayam umur 3 bulan (Pullet/dewasa) yang tinggal dua bulan lagi siap untuk bertelur.

\section{Biaya Operasional}

Biaya operasional adalah biaya yang diperlukan untuk menjalankan kegiatan produksi dan biaya yang rutin dikeluarkan selama proses produksi berlangsung. Untuk lebih jelasnya mengenai biaya operasional yang dikeluarkan oleh peternak ayam ras petelur dipaparkan pada Tabel 4

Tabel 4. Biaya Operasional Usaha Peternakan Ayam Ras Petelur Di Kecamatan Praya Barat Daya Kabupaten Lombok Tengah

\begin{tabular}{|c|c|c|c|c|c|}
\hline \multirow[b]{2}{*}{ NO } & \multirow[b]{2}{*}{ Uraian } & \multicolumn{2}{|l|}{ Peternak Tipe I } & \multicolumn{2}{|l|}{ Peternak Tipe II } \\
\hline & & $\begin{array}{l}\text { Biaya }(\mathrm{Rp} / \\
\text { siklus } \\
\text { produksi) }\end{array}$ & $\begin{array}{l}\text { Biaya }(\mathrm{Rp} / \text { total } \\
\text { siklus } \\
\text { produksi) }\end{array}$ & $\begin{array}{l}\text { Biaya }(\mathrm{Rp} / \\
\text { siklus } \\
\text { produksi) }\end{array}$ & $\begin{array}{l}\text { Biaya }(\mathrm{Rp} / \text { total } \\
\text { siklus } \\
\text { produksi) }\end{array}$ \\
\hline 1 & Sarana produksi & 460.451 .000 & 920.902 .000 & 278.579 .013 & 557.194 .027 \\
\hline 2 & Tenaga kerja & 36.000 .000 & 72.000 .000 & 22.000 .000 & 44.000 .000 \\
\hline 3 & Listrik dan air & 480.000 & 960.000 & 1.576 .667 & 3.153 .333 \\
\hline 4 & $\begin{array}{l}\text { Transportasi dan } \\
\text { perbaikan } \\
\text { kandang }\end{array}$ & 4.080 .000 & 8.160 .000 & 1.540 .000 & 3.080 .000 \\
\hline 5 & Bunga modal & 12.800 .000 & 12.800 .000 & - & - \\
\hline Total & & 507.411 .000 & 1.014 .822 .000 & 303.713 .680 & 607.427 .360 \\
\hline
\end{tabular}

Sumber: Data Primer Diolah, (2019)

Penerimaan Usaha Peternakan Ayam Ras Petelur (Cash Inflow)

Penerimaan peternak ayam ras petelur berasal dari penjualan telur ayam sebagai produk utama dan penjualan ayam afkir sebagai produk sampingan. Hal ini sesuai dengan pendapat Triana et al. (2007), penerimaan dari usaha ayam ras petelur diperoleh dari produksi telur, penjualan kotoran, dan ayam afkir. Ayam diafkirkan pada umur 24 bulan ( 2 tahun) atau pada akhir siklus produksi, jadi ayam berproduksi selama 20 bulan. Penerimaan untuk setiap siklus produksi diasumsikan sama. Untuk lebih jelasnya dapat dilihat pada Tabel 5.

Tabel 5 Rata-rata Penerimaan Usaha Peternakan Ayam Ras Petelur di Kecamatan Praya Barat Daya Kabupaten Lombok Tengah

\begin{tabular}{|c|c|c|c|c|c|}
\hline \multirow[b]{2}{*}{ NO } & \multirow[b]{2}{*}{ Uraian } & \multicolumn{2}{|c|}{ Peternak Tipe I } & \multicolumn{2}{|c|}{ Peternak Tipe II } \\
\hline & & $\begin{array}{c}\text { Penerimaan } \\
\text { (Rp/siklus } \\
\text { produksi) }\end{array}$ & $\begin{array}{l}\text { Penerimaan } \\
\text { (Rp/total siklus } \\
\text { produksi) }\end{array}$ & $\begin{array}{c}\text { Penerimaan } \\
\text { (Rp/siklus } \\
\text { produksi) }\end{array}$ & $\begin{array}{l}\text { Penerimaan }(\mathrm{Rp} / \text { total } \\
\text { siklus produksi) }\end{array}$ \\
\hline 1 & Telur & 611.180 .00 & 1.222 .360 .000 & 374.771 .667 & 749.543 .333 \\
\hline 2 & Ayam Afkir & 46.500 .000 & 93.000 .000 & 27.833 .333 & 55.666 .666 \\
\hline & Total & 657.610 .000 & 1.315 .360 .000 & 402.605 .000 & 805.210 .000 \\
\hline
\end{tabular}

Hidayati, N., Maryati, S., dan Zubair, M. 
Sumber: Data Primer Diolah, (2019)

Telur ayam dijual dalam satuan terai, dimana dalam satu terai berisi 30 butir telur yang dijual dengan harga Rp. 32.000 per terai pada bulan ke-5, Rp. 37.000 per terai pada bulan ke- 6, dan Rp. 39.000 per terai pada bulan ke7 sampai bulan seterusnya. Ketika ayam baru mulai bertelur, harga telur disesuaikan dengan ukuran telur, dalam hal ini peternak bertindak sebagai pembuat harga. Sedangkan untuk selanjutnya harga telur mengikuti harga yang berlaku di pasar. Harga untuk ayam afkir sebesar Rp. 50.000 per ekor. Untuk peternak tipe I jumlah ayam ras petelur yang diusahakan sebanyak 1100 ekor dengan jumlah produksi sebanyak 15.820 terai per siklus produksi atau 31.640 terai per total siklus produksi, sedangkan ayam afkir sebanyak 930 ekor per siklus produksi atau 1.860 ekor per total siklus produksi, jadi total penerimaan yang diperoleh sebesar Rp. 657.610 .000 per siklus produksi atau Rp. 1.315.360.000 per total siklus produksi. Sedangkan untuk peternak yang tipe II, rata-rata jumlah ayam yang diusahakan sebanyak 667 ekor dengan rata-rata jumlah produksi sebanyak 9.697 terai per siklus produksi atau 19.393 terai per total siklus produksi, serta rata-rata ayam afkir sebanyak 557 ekor per siklus produksi atau 1.114 per total siklus produksi, sehingga rata-rata penerimaan yang diperoleh sebesar Rp. 402.605 .000 per siklus produksi atau Rp. 805.210.000 per total siklus produksi.

\section{Analisis Pendapatan Usaha Peternakan Ayam Ras Petelur}

Analisis pendapatan adalah alat analisis yang digunakan untuk mengetahui Perkembangan usaha pada periode waktu tertentu (Tambunan, 2015). Pendapatan diperoleh dari penerimaan dikurangi dengan total biaya (biaya tetap dan biaya variabel). Komponen yang terdapat dalam analisis pendapatan adalah penerimaan, biaya tetap dan biaya variabel. Rata-rata pendapatan usaha peternakan ayam ras petelur di Kecamatan Praya Barat Daya dapat dilihat pada Tabel 6 .

Tabel. 6 Rata-Rata Pendapatan Usaha Peternakan Ayam Ras Petelur Untuk 2 Siklus Produksi di Kecamatan Praya Barat Daya Kabupaten Lombok Tengah

\begin{tabular}{llrr}
\hline No & Uraian & Peternak Tipe I & Peternak Tipe II \\
\hline $\mathbf{1}$ & Penerimaan & 1.222 .360 .000 & 805.210 .000 \\
\hline $\mathbf{2}$ & Biaya Tetap & 154.597 .933 & 21.864 .319 \\
$\mathbf{3}$ & Biaya Variabel & 1.045 .599 .000 & 702.845 .693 \\
\hline $\mathbf{4}$ & Pendapatan & 112.823 .067 & 80.499 .988 \\
\hline
\end{tabular}

Sumber: Data Primer Diolah, (2019)

Tabel 6 menunjukan bahwa nilai pendapatan yang diperoleh peternak tipe I lebih besar dibandingkan dengan peternak tipe II. Hal ini disebabkan karena jumlah populasi ayam yang dipelihara oleh peternak tipe II lebih banyak. Hal ini sesuai dengan pendapat Maliki et al (2017), semakin meningkatnya populasi ayam petelur yang dibudidayakan maka semakin tinggi pula pendapatan yang diperoleh peternak.

\section{Analisis Kelayakan Finansial Usaha Peternakan Ayam Ras Petelur}

Kelayakan finansial suatu usaha peternakan dapat dilihat dari perhitungan aliran cash flow usaha tersebut. Perhitungan aliran cash flow, dibagi menjadi dua yaitu cash inflow (benefit) dan cash outflow (biaya). Berdasarkan hasil penelitian, komponen yang digunakan untuk analisis kelayakan finansial ini terdiri dari biaya investasi, biaya operasional, dan penerimaan. Dalam penelitian ini kriteria kelayakan investasi yang digunakan adalah $N P V$, IRR, Net $B / C$, dan $P B P$. Hasil perhitungan kriteria-kriteria investasi tersebut dapat dilihat pada Tabel 7.

Tabel 7. Hasil Analisis Kelayakan Usaha Peternakan Ayam Ras Petelur di Kecamatan Praya Barat Daya Kabupaten Lombok Tengah Selama 2 Siklus Produksi

\begin{tabular}{|c|c|c|c|c|}
\hline \multirow{3}{*}{ NO } & \multicolumn{4}{|c|}{ Usaha Peternakan Ayam Ras Petelru } \\
\hline & \multirow{2}{*}{ Uraian } & \multicolumn{2}{|c|}{ Hasil Analisis 2 siklus produksi } & Kriteria \\
\hline & & Peternak Tipe I & Peternak Tipe II & \\
\hline$\overline{1}$ & NPV & 76.131 .921 & 13.987 .52 & $>0$, Layak \\
\hline 2 & IRR & 2,58 & 1,53 & $>$ i', Layak \\
\hline 3 & Net B/C & 1,33 & 1,08 & $>1$, Layak \\
\hline 4 & PBP & 8 bulan 27 hari & 11 bulan 13 hari & $<$ Umur proyek, Layak \\
\hline
\end{tabular}

Sumber: Data Primer Diolah, (2019) 
Ketetangan: I' $=$ DF $12 \%$ adalah tingkat suku bunga bank pada saat penelitian

Discount faktor yang digunakan merupakan tingkat suku bunga bank yang berlaku pada saat penelitian yakni $12 \%$ per tahun atau $1 \%$ per bulan. Nilai NPV sebesar Rp. 76.131.921, artinya bahwa nilai pendapatan bersih yang diterima peternak selama umur usaha ini bila dibandingkan dengan nilai uang sekarang adalah sebesar $\mathrm{Rp}$. 76.131.921 untuk peternak tipe I. Rata-rata nilai NPV sebesar Rp. 13.987.152, artinya bahwa nilai pendapatan bersih yang diterima peternak selama umur usaha ini bila dibandingkan dengan nilai uang sekarang adalah sebesar Rp. 13.987.152 untuk peternak tipe II.

IRR merupakan nilai yang menggambarkan tingkat pengembalian modal bagi pemilik perusahaan yang melakukan investasi selama proyek berlangsung (Sianturi, 2004). Sebuah investasi usaha peternakan akan dinyatakan layak apabila nilai IRR lebih besar dari nilai pengembaliannya. Secara matematis dapat dihitung sebagai berikut :

$$
\begin{aligned}
& I R R=i_{1}+\frac{N P V_{1}}{i \dot{i} \dot{C}} \\
& I R R=0,01+\frac{76 \cdot 131 \cdot 921}{(76 \cdot 131 \cdot 921+1 \cdot 190 \cdot 699)} \times(0,026-0,01) \\
& I R R=0,01+0.0158 \\
& I R R=0,0258=2,58 \% \text { per bulan (Peternak tipe I). } \\
& I R R=i_{1}+\frac{N P V_{1}}{\dot{i} \dot{i}} \\
& I R R=0,01+\frac{13 \cdot 987 \cdot 152}{(13 \cdot 987 \cdot 152+1 \cdot 059 \cdot 037)} \times(0,016-0,01) \\
& I R R=0,01+0,0054 \\
& I R R=0,0154=1,54 \% \text { per bulan (Peternak tipe II). }
\end{aligned}
$$

Hasil perhitungan IRR menunjukkan bahwa nilai IRR usaha peternakan ayam ras petelur untuk peternak tipe I adalah sebesar $2,58 \%$ per bulan. Nilai IRR sebesar 2,58\% per bulan lebih besar dari OCC yaitu tingkat suku bunga bank sebesar $12 \%$ per tahun atau $1 \%$ per bulan. Sedangkan nilai IRR untuk peternak tipe II adalah sebesar $1,54 \%$ per bulan lebih besar dari OCC sebesar $12 \%$ per tahun atau $1 \%$ per bulan. Berdasarkan nilai IRR tersebut dapat dikatakan bahwa usaha peternakan ayam ras petelur di Kecamatan Praya Barat Daya layak untuk dikembangkan, karena investasi yang ditanamkan dalam usaha ini mampu memberikan keuntungan sebesar 2,58\% per bulan untuk peternak tipe I dan $1,54 \%$ per bulan untuk peternak tipe II.

Analisis Net $\mathrm{B} / \mathrm{C}$ digunakan untuk menghitung pendapatan bersih sekaranguntuk setiap satu rupiah yang diinvestasikan dalam usaha peternakan ayam ras petelur (Abadi, 2017). Rumus Net B/C adalah NPV positif $(+$ ) dibagi dengan NPV negatif (-), maka hasil perhitungan adalah 1,33 untuk peternak tipe I, sedangkan untuk peternak tipe II nilai net B/C sebesar 1,08. Berdasarkan analisis Net B/C maka usaha ayam ras petelur di Kecamatan Praya Barat Daya dikatakan layak secara finansial.

Analisis payback period sangat perlu dilakukan untuk mengetahui seberapa lama waktu yang diperlukan untuk menutupi biaya investasi yang dikeluarkan. Perhitungan PBP dapat dilihat pada persamaan berikut :

$$
\begin{gathered}
P B P=T_{p-1}+\frac{\sum_{i=1}^{n} \overline{I i}-\sum_{i=1}^{n} \overline{B_{i c p-1}}}{\overline{B_{p}}} \\
P B P=9+\frac{140.611 .757-142.685 .488}{31.069 .448}
\end{gathered}
$$

$P B P=8,93$ (Peternak tipe I)

$$
P B P=T_{p-1}+\frac{\sum_{i=1}^{n} \overline{I i}-\sum_{i=1}^{n} \overline{B_{i c p-1}}}{\overline{B_{p}}}
$$




$$
P B P=4+\frac{135.791 .027-145.399 .249}{17.819 .278}
$$

$P B P=11,46$ (Peternak tipe II)

Berdasarkan hasil perhitungan investasi sebesar Rp. 145.626.000 yang dikeluarkan oleh peternak tipe I dapat dikembalikan dalam waktu 8 bulan 27 hari dengan asumsi umur usaha selama 4 tahun atau 48 bulan. Sedangkan untuk peternak tipe II biaya investasi yang dikeluarkan sebesar Rp. 148.735.833 dapat dikembalikan dalam waktu 11 bulan 13 hari. Hal ini menunjukan bahwa usaha yang dijalankan layak, karena waktu yang dibutuhkan untuk pengembalian dana investasi relatif sangat.

\section{Kendala-Kendala dalam Usaha Peternakan Usaha Ayam Ras Peterlur}

Kendala yang dimaksud dalam penelitian ini adalah masalah yang dihadapi oleh peternak yang dapat mempengaruhi pelaksanaan usaha peternakan ayam ras petelur di Kecamatan Praya Barat Daya. Kendala-kendala yang dihadapi peternak adalah serangan penyakit, cuaca tidak menentu, dan harga pakan yang mahal. Dalam penelitian ini 1 peternak bisa mengalami 1 sampai 3 kendala tersebut. Rinciannya disajikan pada tabel 8 .

Tabel. 8 Kendala-kendala yang Dihadapi Peternakan Ayam Ras Petelur di Kecamatan Praya Barat Daya Kabupaten Lombok Tengah

\begin{tabular}{llrr}
\hline NO & Kendala & Orang & Persentase (\%) \\
\hline $\mathbf{1}$ & Serangan Penyakit & 3 & 75 \\
$\mathbf{2}$ & Cuaca tidak menentu & 4 & 100 \\
$\mathbf{3}$ & Harga Pakan Mahal & 4 & 100 \\
\hline
\end{tabular}

Sumber: Data primer Diolah, (2019)

Tabel 8 Menunjukan bahwa kendala terbesar yang dihadapi peternak ayam ras petelur di Kecamatan Praya Barat Daya Kabupaten Lombok Tengah adalah cuaca tidak menentu dan harga pakan mahal. Jumlah responden yang mengalami kendala tersebut sebanyak 4 orang (semua responden) dengan persentase sebesar $100 \%$. Kemudian diikuti dengan serangan penyakit dengan jumlah responden yang mengalami hal tersebut sebanyak 3 orang atau $75 \%$.

\section{KESIMPULAN DAN SARAN}

\section{Kesimpulan} berikut:

Berdasarkan hasil penelitian dan analisis yang telah dilakukan, maka dapat ditarik kesimpulan sebagai

1. Rata-rata pendapatan usaha peternakan ayam ras petelur di Kecamatan Praya Barat Daya Kabupaten Lombok Tengah dalam dua kali siklus produksi sebesar Rp. 112.823 .067 dengan jumlah ayam yang diusahakan sebanyak 1100 ekor untuk peternak tipe I. Sedangkan untuk peternak tipe II, rata-rata pendapatan yang diperoleh sebesar Rp. 80.499 .988 per dua kali siklus produksi dengan rata-rata jumlah ayam sebanyak 667 ekor.

2. Usaha peternakan ayam ras petelur di Kecamatan Praya Barat Daya Kabupaten Lombok Tengah layak untuk dikembangkan, berdasarkan hasil perhitungan NPV, IRR, Net B/C, dan PBP.

3. Kendala yang dihadapi oleh peternak di Kecamatan Praya Barat Daya Kabupaten Lombok Tengah adalah serangan penyakit, cuaca tidak menentu dan tingginya harga pakan.

Saran

Berdasarkan hasil penelitian yang telah dilaksanakan maka diajukan beberapa saran sebagai berikut:

1. Kepada peternak sebaiknya melakukan pengembangan usaha dengan menambah jumlah ayam yang diusahakan, dengan memperhatikan kepadatan kandang, sehingga tingkat pendapatan yang diperoleh akan lebih tinggi.

2. Kepada peternak sebaiknya menggunakan ayam umur 2 hari pada awal pemeliharaan dan jenis pakan yang digunakan adalah pakan campuran (buatan sendiri) sehingga dapat menekan biaya produksi yang dikeluarkan.

3. Kepada peternak dalam melakukan kegiatan produksi sebaiknya mencatat setiap pengeluaran dan penerimaan yang diperoleh, sehingga dapat mengetahui tingkat perkembangan usahanya. 
4. Kepada pemerintah daerah untuk dapat membangun industri pabrik pakan ternak khususnya pakan ternak ayam agar harga pakan dapat lebih murah.

\section{DAFTAR PUSTAKA}

Sekretariat Jenderal Kementerian Pertanian. 2015. Keputusan Menteri Pertanian Republik Indonesia. https://pusvetma.ditjennak.pertanian.go.id. [20 Desember 2018].

Kasmir., Jakfar. 2003. Studi Kelayakan Bisnis. Edisi 2. Prenada Media Group. Jakarta.

Pasaribu, A.M. 2012. Perencanaan dan Evaluasi Proyek Agribisnis Konsep dan Aplikasi. Andi Offset. Yogyakarta.

Ibrahim, H.M.Y. 1997. Studi Kelayakan Bisnis. PT Rineka Cipta. Jakarta

Maulana, F.H., E, Prasetyo., W, Sarenggat. 2017. Analisis Pendapatan Usaha Peternakan Ayam Petelur Sumur Banger Farm Kecamatan Tersono Kabupaten Batang. Mediagro.13 : 1-12

Mustika, N.D., 2011. Analisis Pendapatan Usaha Peternakan Ayam petelur Di Kecamatan Takeran Kabupaten Magenta. [Skripsi, published]. Universitas Sebelas Maret. Surakarta.

Triana, A., T.Salam, M.Muis.2007. Analisis Pendapatan Usaha Peternakan Ayam Ras Petelur Periode Layer di Kecamatan Maros. Agrisistem. $3: 11-25$

Tambunan, A., 2015. Analisis Kelayakan Usaha Ayam Petelur (Studi Kasus Perusahaan X Di Desa Gobang, Kecamatan Rumpin Kabupaten Bogor). [Skripsi, Published]. Fakultas Ekonomi Dan Manajemen Institut Pertanian Bogor. Bogor.

Maliki, M.L., A, Setiadi., W, Sarengat. 2017. Analisis Profitabilitas Usaha Peternakan Ayam Petelur Di Suyatno Farm Desa Kalisidi Kecamatan Ungaran Barat Kabupaten Semarang. Mediagro. 13: 49 - 60

Sianturi, E.C., 2011. Analisis Kelayakan Usaha Ayam Ras Petelur Pada Dian Layer Farm Di Desa Sukadamai Kecamatan Darmaga Kabupaten Bogor. [Skripsi, published]. Fakultas Ekonomi dan Manajemen Institut Pertanian Bogor. Bogor.

Abadi, M., Taridala, S.A., Nafiu, L., 2017. Evaluasi Kelayakan Finansial Ayam Ras Petelur Pada Cv. Bintani Poultry Shop Kendari. Buletin Peternakan. 41: 355-364 